\title{
Internal barriers to supply chain management implementation in a South African traditional university
}

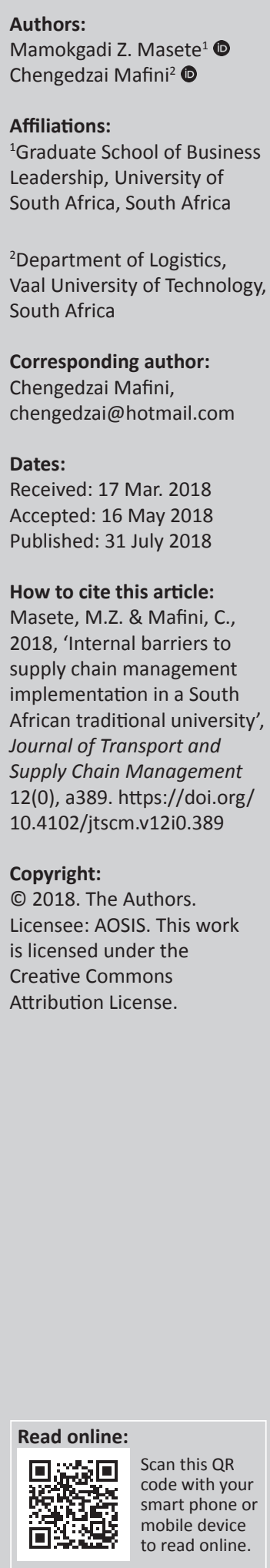

Background: The demand for higher education in South Africa continues to increase, placing pressure on public higher education institutions to satisfy this demand. Supply chain management is one of the practices that may be implemented to ensure that public universities improve their operations and can, therefore, meet the increased demand for higher education in the country.

Objectives: This study aimed to explore the barriers to the implementation of supply chain management practices at a South African public university.

Method: The study used a qualitative case study approach using a sample of 17 members of management and staff at a South African traditional university in the Limpopo Province. Data were collected using a combination of a focus group discussion and semi-structured in-depth interviews.

Results: The study generated eight themes that embody the barriers to the implementation of supply chain management at the institution. These themes were labelled as stakeholder buy-in, knowledge of supply chain management, supply chain systems and processes, procurement policy and practices, implementation of supply chain management, stakeholder change management, human resource management and organisational culture.

Conclusion: Various internal barriers impair the implementation of supply chain management practices at the institution. Administration at the institution has invested limited resources, time and initiatives to ensure the successful implementation of supply chain management. The focus should be directed to finding lasting solutions to each of the barriers identified in this study. Further studies should address the issue of external barriers to supply chain management in public higher education institutions.

\section{Introduction}

In most countries, economic growth and development are driven in part by the activities of higher education institutions. According to several scholars (Bhorat, Cassim \& Tseng 2016; Boulton \& Lucas 2011; Pouris \& Inglesi-Lotz 2014), higher education institutions are the primary vehicle for the production and improvement of human capital. Also, the higher education industry serves as a major means for the development and maintenance of knowledge bases through research and innovation, as well as the circulation and conservation of knowledge through various forms of interactions with stakeholders (Nicolaides 2014). In South Africa, the National Development Plan states that the higher education industry produces skilled graduates to meet both the current and future needs of the economy (National Planning Commission 2012). Besides, universities also generate their own output and employ numerous employees within different professions, at different qualification and skills levels (Kimenyi 2011; Uyarra 2010). Perhaps one of the profound indirect economic impacts of universities is their procurement of various products from other sectors in support of their operational activities, which actuates economic activity within those industries (Dlamini 2016). The suppliers of the universities buy from other suppliers to fulfil university orders, and these suppliers, in turn, buy from others, resulting in a ripple effect that stimulates the economy (Pouris \& Inglesi-Lotz 2014).

The majority of higher education institutions in South Africa are public universities, which are further classified as traditional, comprehensive and universities of technology (Bunting \& Cloete 2010). Sustainability of these public universities is critical if their economic significance is to be maintained. Among those practices that may be implemented to ensure that public universities 
are successful is supply chain management (SCM). As underscored by Dlamini and Ambe (2013), the use of SCM to acquire goods and services is an efficient tool for addressing the challenges facing the higher education industry. However, higher education institutions have the responsibility of selecting the most appropriate SCM framework to ensure compliance not only to policies and procedure but also to choose a structure that results in the efficient use of limited organisational resources for improved service delivery (Nel 2010; PricewaterhouseCoopers 2016).

The South African higher education environment faces a multitude of SCM-related issues that are becoming increasingly complex and require unique and strategic solutions. According to some reports (Ambe \& BadenhorstWeiss 2011; KPMG South Africa 2016a; Mkhize 2004), some of these challenges include the poor implementation of SCM practices, the need for comprehensive policies, poor planning for annual procurement and the lack of skills and capacity. In the entire public sector, SCM has of late been placed under the spotlight because of the emphasis on financial management reform (Fourie 2015). Public higher education institutions have to follow suit, and universities can at times have a traditional approach to SCM that does not maximise cost-efficiency in a legally compliant manner (KPMG South Africa 2016a). This attracts the challenge of ensuring that SCM practices in these institutions are both useful and implemented in line with the available national policies.

\section{Problem statement}

This study aimed to explore the internal barriers to the implementation of SCM at a South African public university. The major research question addressed in this article reads as follows: 'What are the major internal barriers faced by the institution in its implementation of SCM?' There is a need for higher education to transition its SCM units from being procurement functions to strategic assets (Sallaudin et al. 2015). However, it is vital that comprehensive capabilities, policies, processes, procedures and systems duly bolster any positive changes in the higher education industry (Akyel, Polat \& Arslankaya 2012; Fooladvand, Yarmohammadian \& Shahtalebi 2015). Improving and optimising SCM will improve the financial position of a university, decrease the risks of non-compliance and better place the university to defend its policy direction as a respectable corporate citizen with its various stakeholders (Dlamini \& Ambe 2013). This attracts the necessity to continue exploring new methods for increasing the effectiveness of SCM in higher education, to realise its benefits. Still, as reported by the Department of Higher Education and Training (DHET 2014), South African public universities have been mandated with an increased duty to implement good governance sustainability and corporate citizenships. However, the ability to comply with the best governance, financial and general management practices under today's unpredictable economic conditions is primarily dependent on the availability of relevant information (PricewaterhouseCoopers 2016). Continued research is necessary then to investigate how higher education institutions may be able to adopt and implement SCM in line with existing best practices.

Despite the emphasis placed on SCM by the South African government, academic research has shown that few public universities have adopted SCM in terms of best practices. Previous research has demonstrated that most institutions do not apply SCM best practices (Dlamini 2016; Lau 2007; Owusu-Bio, Manso \& Adiwokor 2015). As highlighted by the Parliamentary Monitoring Group (2013), South African public universities face numerous challenges, such as poor governance, the lack of leadership, fraud and corruption. Consequently, several South African public universities have been placed under administration at some point during their existence after experiencing financial crises. In agreement, Dlamini and Ambe (2013) underscore that the ineffective application of SCM practices by South African public universities has resulted in cases of maladministration and the misappropriation of funds. As reported by Sallaudin et al. (2015), the effective and efficient application of SCM presents an excellent opportunity that could result in sustainable growth and success for and organisation. This study, therefore, contributes to the literature on SCM in higher education in South Africa by generating more knowledge that can be directed towards addressing the current challenges facing the industry.

The remaining sections of this article are organised as follows: The next section provides an overview of the theoretical insights that are important to this study. This section is followed by a discussion of the research methodology and an outline of the findings of the study. The final sections of the article focus on the conclusions, managerial implications as well as limitations and suggestions for future research.

\section{Theoretical overview}

This section covers three key issues in the discourse of the implementation of SCM in public universities. These are (1) the higher educational environment in South Africa, (2) public supply chain management in South Africa and (3) supply chain management in South African public universities.

\section{The higher educational environment in South Africa}

The South African higher education sector operates under the supervision of the DHET. The critical performance area of the DHET is the harmonisation of all post-secondary education in South Africa to achieve the government's objective of producing a skilled and capable workforce (Kotecha, WilsonStrydom \& Fongwa 2012). An important category among the various higher education providers is public universities. Currently, there are 26 public universities in South Africa, distributed within the different provinces of the country. These public universities are further classified as 12 traditional universities, six comprehensive universities, six universities of technology and two institutes of higher education (South Africa Education 2018). These public institutions provide their 
services to nearly a million students across a wide range of academic fields (Kotecha et al. 2012).

To accomplish the objectives of higher education that are promulgated in the existing legislative framework, public universities in South Africa are expected to have stable governance structures as well as vibrant, prudent and accountable management (De la Rey 2015). As quasiautonomous organs of state, public universities are expected to use the current legislative framework to develop, benchmark and implement best practices (PricewaterhouseCoopers 2016). In recent years, the Office of the Auditor General of South Africa (AGSA) has introduced SCM as a specific review area in all public higher education institutions' financial audit (AGSA 2011). This inclusion is intended to promote the development and implementation of efficient SCM processes and internal controls. From this process, it is envisaged that SCM will be implemented reasonably, equitably, transparently, competitively and cost-effectively. It is further anticipated that public universities will excel in their compliance with legislation, thereby minimising the possibilities of fraud, corruption and favouritism as well as unfair and irregular practices in these institutions (National Treasury 2015; Parliamentary Monitoring Group 2013).

\section{Public supply chain management in South Africa}

Progressively, it is more accepted that public SCM is an essential practice in the management of public resources. It performs a strategic role in the public sector's ability to deliver on its obligations of service delivery in line with the government's service delivery as dictated by the South African constitution (Matolong 2015). In South Africa, public SCM is governed under the auspices of a legislative framework which states as its objective the need to be fair, equitable, transparent and cost-effective (Dlamini \& Ambe 2012). Some of the major pieces of legislation related to public SCM include the Public Finance Management Act 1 of 1999, Preferential Procurement Policy Framework Act 5 of 2000, Broad-Based Empowerment Act 53 of 2003 and the Prevention and Combating of Corrupt Activities Act 12 of 2004 (Turley \& Perera 2014).

The public SCM arena in South Africa faces numerous challenges, most of which are well acknowledged in the literature. According to the National Treasury (2015), it appears that stakeholders do not comprehend well the strategic significance of SCM. Organisational structures within which public SCM operates are cumbersome and in many cases problematic, characterised by incapable leadership, demotivated staff and high staff turnover (Watermeyer 2011). Other challenges include uncertainties related to role conflict between technical staff and political appointees, the lack of integrated planning, and the failure to develop mechanisms and processes to manage both internal and market-related dynamics (Burger 2016; Dlamini 2016; KPMG South Africa 2016a). Moreover, it appears that the available rules and regulations are often ambiguous and confusing to implement for many stakeholders (Ambe \& Badenhorst-Weiss 2012). The ultimate challenge relates to the entrenched lack of accountability, fraud and corruption, leading to substandard service delivery throughout the country (Universities South Africa 2015). Stakeholders in the South African public sector, therefore, face the challenge to develop and apply solutions that will disrupt the status quo and ensure that SCM contributes constructively to the achievement of the government's socio-economic development imperatives.

\section{Supply chain management in South African public universities}

Upon realisation of the importance of SCM in the higher education environment, most public universities in South Africa have established a service division which concentrates on the implementation of SCM within their institutions. This division, which is usually well structured, is typically manned by a full complement qualified SCM professionals. The most significant SCM activity undertaken by this SCM division in a public university would be to oversee the procurement of goods and services that are required by the different sections and departments of the institution (Hassan et al. 2015). Typically, public universities in South Africa have an annual procurement spend running into hundreds of millions of rands per institution. For instance, in the 2014 financial year, the aggregate spend by South Africa's higher education institutions was nearly R25.6 billion (Business Tech 2015). The utilisation of these funds involves the implementation of other SCM activities that include supplier relationship management, demand management, order processing, as well as customer relationship and service management (Poluha 2016). Additionally, SCM in public universities involves a well-structured Motor Fleet Division which oversees the transportation and logistics function within the institution.

In South African public universities, the procurement of large-value items is implemented through the tender or competitive bidding system, which requires the engagement and consultation of various internal and external stakeholders who represent multiple parties that have vested interests in the running of the university (KPMG South Africa 2016b). Different stakeholders may be invited to participate at various stages in decision-making processes regarding the evaluation of suppliers who should be awarded the contract in the tender process (Gopalakrishnan 2015). Most university procurement policies should specify the representatives of different special interest and stakeholder groups that have to be invited to participate in such processes (PricewaterhouseCoopers 2015). Stakeholders may also be consulted as sources of information regarding important issues such as the existence of a need for a particular product or service, possible and realistic costing of goods and services and suitability of suppliers, among others (Al-Turki et al. 2008). Without this extensive consultation, most SCM processes may result in conflict as stakeholders feel that the procurement process is not executed transparently and that the decisions made should be reversed. Therefore, for the procurement process to operate smoothly and successfully in public universities, the input and voice of various stakeholders is required throughout. 


\section{Research methodology}

This section discusses the research approach and design, participants, procedures for data collection, data analysis, measures of trustworthiness and ethical considerations.

\section{Research approach and design}

The research methodology of choice for this project was a qualitative approach using the case study design. An exploratory qualitative research design was used for this study, as motivated by a need to understand the in-depth processes that operate within the subject of the research study (Yates \& Leggett 2016). Qualitative research often emphasises understanding the processes of an organisation rather than predicting outcomes and is conducted within the local context in which the phenomena under study occurs (Blumberg, Cooper \& Schindler 2014; Leedy \& Ormrod 2015). This applied to this study, which directed its emphasis to the understanding of barriers embedded in the internal organisational processes at a single South African public university. The chosen research method involved the exploration of the situation, collection of data, and analysis and interpretation of results (Mason 2010).

\section{Participants}

The target population in this study consisted of procurement personnel, members of the operational tender committee of council, university management and management consultants at a South African public university based in the Limpopo Province. The categories and numbers of people included in the target population are indicated in Table 1.

The actual sample was drawn using a sample frame obtained from the human resources database at the institution. According to Padget (2016), the sampling frame is a list of elements from which the study's sample is drawn. In this study, the sample frame consisted of a list of management, employees, external consultants and other important role players involved in SCM at the higher education institution. In choosing the actual sample, a non-probability purposive sampling technique was used. Non-probability sampling consists of the selection of sample elements based on the judgement of the researcher (Patton 2015). A purposive sampling technique is one in which only those population elements that serve the objectives of the study will be chosen (Petty, Thompson \& Stew 2012). In this study, only members of the university who have some knowledge of SCM or have participated in decisions related to SCM were selected to participate in the study. The final sample composed of management, academics, consultants and staff in the

TABLE 1: Profile of target population.

\begin{tabular}{lc}
\hline Category & Number \\
\hline Procurement personnel & 5 \\
Operational tender committee of council members & 8 \\
Management & 70 \\
Supply chain management consultants & 10 \\
\hline Total & 93 \\
\hline
\end{tabular}

procurement department in the institution. In line with the suggestion by Creswell (2013), there was no predetermined sample size in this qualitative study. Instead, interviews were conducted until the point of saturation, which is the point at which the responses of participants became almost similar, indicating that no further data collection was necessary.

\section{Procedures for data collection}

For this study, the primary data were collected through a combination of focus group interviews and semi-structured in-depth interviews. A focus group can be defined as a guided, monitored and recorded group discussion on a particular topic organised for research purposes (Saunders, Lewis \& Thornhill 2015). Focus groups also generate a rich understanding of participants' experiences and beliefs (Gill et al. 2008). One focus group session was conducted in September 2017 at a designated location within the main campus of the university and lasted for close to $45 \mathrm{~min}$. The focus of the discourse was on general questions about the research topic. The focus group discussion was recorded through a combination of digital voice recorders and notes taken by the principal researcher, who also performed the role of a guide, monitor and timekeeper during the discussion. Eight people who were part of the target population attended the focus group discussion. Permission to record the discussion was requested from the participants before proceedings started.

Semi-structured in-depth interviews involving 17 participants followed the focus group discussion. In-depth interviews are face-to-face encounters between the researcher and informants directed towards understanding informants' perspectives on their lives, experiences or situations as expressed in their own words (Flick 2014). The interviews, which were held in the English language, were aimed at exploring the views, experiences, beliefs and motivations of the participants concerning the objectives of this study. In addition to being neutral, sensitive and understandable, the interview questions were open-ended as they required more than a yes or no answer (Leedy \& Omrod 2015). An interview guide was designed to ensure that the interviewer focused on the same issues consistently and asked the same questions in every interview, which enhanced the comparability of the multiple conversations (Blumberg et al. 2014).

During the interviews, questions were ordered to enable ease of flow, while allowing the interviewer to deviate when necessary without compromising the quality of the responses from participants. In line with suggestions by Doody and Noonan (2013), the interview questions were formulated along the lines of behaviour or experience, opinion or value, knowledge, sensory experience and demographic or background details. Permission to record these proceedings was requested from each participant before the interviews. During and after the interviews, the principal researcher actively took some field notes about any observations, thoughts and ideas regarding the discussion. Interviews were conducted until a point of saturation, which occurred at 17 participants, whereby there was no need to continue collecting the data as the process was now producing similar views. 


\section{Data analysis}

In preparation for analysis, the voice recordings of both the focus group discussions and the in-depth interviews were transcribed into text format (Flick 2014). The services of a professional transcriber were used for the transcription. Once the transcripts were available, a content analysis was initiated to analyse the data. The central premise of content analysis is the selective reduction of text to categories including words or a set of phrases on which researchers concentrate (Mayer 2015). These specific words or patterns are indicators of the research questions and determine the level of analysis (Jonker \& Pennning 2010). The interview transcripts were read several times over to identify the categories and the themes (main points) originating from the data. The themes were then classified into more manageable sub-themes, after which a summarised table of the central themes arising from the participants' stories was drawn up (Bryman 2015). These themes represent the findings of the study from which conclusions were drawn. A computer program (ATLAS.ti version 8 ), which is useful when dealing with large sections of qualitative data in the form of audio, visual and text (Mayer 2015), was used in the data analysis.

\section{Measures of trustworthiness}

Trustworthiness is concerned with how a researcher can determine confidence in the findings of his or her research and how observers can be confident that the conclusions presented are genuine (Cohen, Manion \& Morrison 2011). Four measures of trustworthiness, namely credibility, transferability, confirmability and dependability, were applied in this study. Credibility is defined as the extent to which the presented findings are a correct representation of the views of the participants (Bhattacherjee 2012). To ensure that the findings of the study are credible, the data triangulation approach was used, in which data were collected from different sources, such as secondary data sources as well as from the participants themselves, and through the combination of focus group interviews and structured interviews (Bhattacherjee 2012; Moretti et al. 2011). Conformability is the degree to which others can confirm the research findings (Bryman 2015). For this study, member checks were performed by sending back the research findings to research participants for evaluation and corrective suggestions to ensure the confirmability of the research (Anney 2015).

Transferability is the extent to which the research findings of a specific study can be applied to theory formulation, practice and future research, that is, another context and other respondents (Anney 2015; Moon et al. 2016). To ascertain transferability, the current research environment and methods were compared to similar settings elsewhere within the South African public higher education sector. As defined by Moon et al. (2016), dependability is the extent to which the research findings are consistent and stable over time. To ascertain dependability in this study, audit tracks were performed. An audit track is a process of continuously testing the data and its interpretative themes as obtained from multiple sources (Anney 2015). In this study, the data transcripts were sent back to research participants for evaluation and corrective suggestions. This reduced the bias of the researchers when analysing and interpreting results.

\section{Ethical considerations}

The study was conducted consistently with the norms and acceptable standards of research. An introductory letter was written and issued to participants assuring them that confidentiality and privacy would be maintained and that their responses would be recorded anonymously (Blumberg et al. 2014; Petty et al. 2012). Throughout the study, the actual names of the participants were treated anonymously, and the identities of the respondents were treated with strict confidentiality. The benefits of the study, as well as the rights of the participants, were explained to each participant before their participation. Participants were requested to sign a consent form, which indicated that their participation in the study was voluntary. In addition, participants were allowed to withdraw from the study at any period. The consent of participants was sought regarding the use of an audio recorder during interviews.

\section{Findings of the study}

This section provides detail on the description of the sample and the themes emerging from the study.

\section{Description of the sample}

The stakeholders of the higher education institution who were involved in this study included executive, senior and middle management, a consultant, senior academics and staff from administrative support units. The demographic profile of these participants is presented in Table 2.

Table 2 shows that eight males and nine females participated in the study. Four of the participants were between the ages of 30 and 40; five were between the ages of 40 and 50 and six

\begin{tabular}{|c|c|c|c|c|c|}
\hline $\begin{array}{l}\text { Participant } \\
\text { No. }\end{array}$ & Position & Gender & $\begin{array}{l}\text { Age } \\
\text { group }\end{array}$ & $\begin{array}{l}\text { Employment } \\
\text { period (years) }\end{array}$ & $\begin{array}{l}\text { Highest } \\
\text { qualification }\end{array}$ \\
\hline 1 & Manager & $\mathrm{F}$ & $30-40$ & 5 & Bachelors \\
\hline 2 & Manager & $\mathrm{F}$ & $40-50$ & 7 & Masters \\
\hline 3 & Director & $\mathrm{F}$ & $50-60$ & $>20$ & Bachelors \\
\hline 4 & Consultant & $M$ & $50-60$ & 1 & Bachelors \\
\hline 5 & Manager & $\mathrm{F}$ & $30-40$ & 8 & Honours \\
\hline 6 & Director & M & $40-50$ & $>20$ & $\mathrm{PhD}$ \\
\hline 7 & Director & $\mathrm{F}$ & $40-50$ & 7 & Masters \\
\hline 8 & Executive & $\mathrm{M}$ & $50-60$ & $>20$ & Masters \\
\hline 9 & Senior lecturer & $F$ & $50-60$ & $>20$ & Masters \\
\hline 10 & Executive & $\mathrm{M}$ & $40-50$ & 5 & PhD \\
\hline 11 & Executive & $\mathrm{F}$ & $50-60$ & $>20$ & $\mathrm{PhD}$ \\
\hline 12 & Director & M & $30-40$ & 4 & Masters \\
\hline 13 & Executive & $\mathrm{F}$ & $50-60$ & $>20$ & $\mathrm{PhD}$ \\
\hline 14 & Director & $\mathrm{F}$ & $30-40$ & 8 & Masters \\
\hline 15 & Director & M & $50-60$ & $>20$ & $\mathrm{PhD}$ \\
\hline 16 & Manager & M & $50-60$ & $>20$ & Honours \\
\hline 17 & Senior lecturer & $\mathrm{M}$ & $40-50$ & 8 & Masters \\
\hline
\end{tabular}

F, female; $M$, male. 
were between the ages of 50 and 60 . Further analyses show that four of the participants had worked at the institution for $<5$ years, whereas five participants had worked in the institution for periods ranging between 7 and 8 years and eight had worked in the institution for $>20$ years. Three of the participants were holders of a bachelor's degree; one was a holder of an honours degree; five were holders of master's degrees, and six participants were holders of doctorates as their highest qualifications. As these participants were highly qualified and were active participants in SCM activities in the institution, it was presumed that their views would be adequate and relevant in providing the required information in this study.

\section{Themes emerging in the study}

Eight themes emerged from the analysis of the empirical data. The themes and their operational definitions are presented in Table 3.

The individual themes and empirical evidence to support these themes are discussed in the next section.

\section{Theme 1: Stakeholder buy-in}

Stakeholder buy-in emerged as the first theme of the study. Most of the participants mentioned that there is a lack of involvement of the different stakeholders of the institution regarding issues related to SCM. Participants acknowledged their lack of awareness of the institution's implementation of SCM practices. They felt that executive management lacks the requisite levels of commitment to consult stakeholders, and therefore, they do not drive critical strategic processes as they should. It also appears that essential stakeholders who

TABLE 3: Themes and operational definitions.

\begin{tabular}{|c|c|c|}
\hline Theme & Description & Operational definition \\
\hline 1 & $\begin{array}{l}\text { Stakeholder } \\
\text { buy-in }\end{array}$ & $\begin{array}{l}\text { This refers to the process of involving the stakeholder } \\
\text { in the institution in the decision-making process for } \\
\text { implementation of SCM with the view of reaching } \\
\text { a broader consensus on the way forward. }\end{array}$ \\
\hline 2 & $\begin{array}{l}\text { Supply chain } \\
\text { management } \\
\text { knowledge }\end{array}$ & $\begin{array}{l}\text { This refers to the extensive understanding of what } \\
\text { SCM entails. }\end{array}$ \\
\hline 3 & $\begin{array}{l}\text { Supply chain } \\
\text { systems and } \\
\text { processes }\end{array}$ & $\begin{array}{l}\text { This entails the use of technology and innovations } \\
\text { to enhance business processes within supply chain } \\
\text { management, also to improve the storage and flow } \\
\text { of information. }\end{array}$ \\
\hline 4 & $\begin{array}{l}\text { Procurement } \\
\text { policy and } \\
\text { practices }\end{array}$ & $\begin{array}{l}\text { This entails the current procurement procedures laid } \\
\text { down by the institution and the processes relating to the } \\
\text { finding, acquisition and purchase of goods and services. }\end{array}$ \\
\hline 5 & $\begin{array}{l}\text { Supply chain } \\
\text { management } \\
\text { implementation }\end{array}$ & $\begin{array}{l}\text { It is the implementation of the active management } \\
\text { of supply chain activities for the delivery of enhanced } \\
\text { customer and economic value through coordinated } \\
\text { control of the flow of goods and services, the planning } \\
\text { and management of all activities involved in sourcing } \\
\text { and procurement, conversion and all logistics } \\
\text { management activities. }\end{array}$ \\
\hline 6 & $\begin{array}{l}\text { Stakeholder } \\
\text { change } \\
\text { management }\end{array}$ & $\begin{array}{l}\text { This is the practical and continuous engagement with } \\
\text { stakeholders to prepare, enable and support them to } \\
\text { successfully embrace change to enhance the successful } \\
\text { institutional implementation of supply chain practices. }\end{array}$ \\
\hline 7 & $\begin{array}{l}\text { Human resource } \\
\text { management }\end{array}$ & $\begin{array}{l}\text { This entails the operational knowledge, skills and } \\
\text { experience in SCM of the institution's current SCM } \\
\text { personnel. }\end{array}$ \\
\hline 8 & $\begin{array}{l}\text { Organisational } \\
\text { culture }\end{array}$ & $\begin{array}{l}\text { This entails a pattern of shared traditions, ideals, } \\
\text { and beliefs, which governs how people behave in the } \\
\text { institution. These have a strong sway on the people in } \\
\text { the institution and often determine how they act and } \\
\text { perform their duties. }\end{array}$ \\
\hline
\end{tabular}

SCM, supply chain management. should be involved in the SCM process, such as academic and non-academic staff, students, alumni and surrounding communities, are somehow left out. This view was highlighted by one of the senior managers, as indicated in the excerpt below:

'The concept of SCM has not yet been institutionalised in the university such that most of the stakeholders are not aware of it and its implications in the university and so they have not yet embraced it.' (P16, male, 54 years)

One of the consultants reiterated this lack of stakeholder buyin into the implementation of SCM. The consultant referred to the fact that there was a general lack of understanding of the role of this function and its importance within the institution:

'If we don't understand the purpose of SCM, it becomes difficult for one to embrace it within the institution.' (P4, male, 52 years)

Some participants lamented the monotonous approach by the institution's management to the implementation of key strategies and the lack of a pro-active approach to change, which was detrimental to the involvement of stakeholders in SCM. Another participant accused management of blindness in issues about the benefits of SCM, which inadvertently contributes to the current dysfunctional situation in the institution.

The inability of management to involve key-stakeholders in SCM activities raises some ethical questions. As mentioned earlier, stakeholders such as academic and non-academic staff, students, alumni and surrounding communities are part of the university's strategic constituencies that have an input in the university's past, current and future state and operations. The decisions made, including those within the SCM area, affect these stakeholders. For instance, the goods and services procured by the institution are used by staff members, both academic and non-academic, to fulfil their daily tasks and responsibilities. Likewise, alumni are also an important cohort to the institution in that wherever they may be presently located, they serve as ambassadors for the institution, and hence, each institution has a division for alumni relations. Similarly, surrounding communities perceive that the institution exists to service them in different ways, such as through providing employment opportunities and meeting their educational needs. As such all these groups of stakeholders are pressure groups that have vested interest in the institution and should be included in important decisions that affect them, such as the procurement of strategic goods and services. The typical approach would be to ensure that these stakeholder groups are represented in these processes and to ensure that they have sufficient information to contribute constructively to the intended SCM transactions. The primary problem relates to the possibility of a deliberate ploy to exclude some stakeholders, given that SCM involves the disbursement of vast amounts of money. Unrestrained expenditures, if unchecked, may result in unethical practices such as fraud, corruption and the manipulation of procurement activities (Dlamini \& Ambe 2013). As some of the representatives of the critical 
stakeholders are excluded from these processes, they are unable to contribute to the SCM transactions occurring, some of which may be irregular. Moreover, conflict is often the norm whenever certain parties feel omitted from such strategic activities, which leads to the further deterioration of relationships between stakeholders. It is therefore essential that SCM policies in place in the institution be augmented by the extensive involvement of stakeholders to avoid diluting the effectiveness of this critical activity.

\section{Theme 2: Supply chain management knowledge}

The knowledge of SCM emerged as the second theme of the study. Participants mentioned that various stakeholders in the institution had a limited understanding and knowledge of what SCM entails, the principal reason being that it is a broad concept that requires a better approach for one to understand it. Participants apportioned the blame of the limited knowledge to the executive management and governance structures of the institution, mentioning that no efforts are made to educate stakeholders on the significance of SCM to the institution. This scenario is tantamount to ineffective organisational SCM competence. These views are encapsulated by the following excerpt from a senior lecturer:

'In South Africa and particularly in this institution I find SCM to be a widely misunderstood concept. People see SCM as a mechanism for purchasing; it is neither viewed as a strategic enabler nor as a full process from the moment the demand exists until we produce our final product.' (P9, female, 53 years)

A procurement manager pointed to the lack of appreciation of SCM by people in different managerial levels of the institution, as shown in the excerpt below:

\begin{abstract}
'Let me categorise the stakeholders and start with the middle managers, and then throw the spotlight on senior managers as well as executive managers. These are some of the critical internal stakeholders, yet some of them do not understand what SCM is despite operating within the supply chain environment. Not every member of the council understands what we mean by SCM.' (P1, female, 39 years)
\end{abstract}

The findings of the study attest that there is a limited grasp of SCM within the institution. This lack of familiarity with such a significant activity is likely to have adverse consequences on the institution as there are various risks associated with knowledge-based inadequacies in any organisation (Ruzic-Dimitrijevic 2014). Firstly, there is a danger that inappropriate cultures, processes and systems will be maintained as stakeholders base their decisions on outdated models. Secondly, there is a risk that stakeholders, both internal and external, who are aware of the prevalence of this limited knowledge of SCM in the institution, may take advantage by engaging in unethical practices, with very little, if any consequences. Thirdly, the risk of declining creativity and innovation in the institution is likely to be high, as stakeholders continue to reinvent the wheel when facing problems that are similar to those encountered in the past (Jennex \& Durcikova 2013). The ultimate result of the lack of SCM knowledge is poor service delivery, as user departments will not obtain the satisfactory service they require from the SCM division. In the current case of a higher education institution, academic activities, which are the core priority, are likely to suffer from a lack of essential resources that should be made available by the SCM division. This is likely to lead to various unsatisfactory outcomes in the university's activities. For instance, because of the lack of teaching resources which are provided through the SCM system, the university risks producing incompetent graduates who meet the institutional requirements for graduation but are ill-prepared to contribute positively to industry afterwards. Additionally, there may be a shortage of resources required to improve other essential academic activities such as research outputs and community engagement, possibly leading to poor institutional reputation. It is necessary then that programmes be put in place to ensure that management at the institution cultivates an atmosphere that facilitates continuous improvement, innovation, learning and problemsolving among those involved in SCM.

\section{Theme 3: Supply chain management systems and processes}

The third theme derived from the empirical data is SCM systems and processes. Participants felt that current SCM systems and processes are deficient, ineffective and unhelpful in enabling the institution to fulfil its mandates. They felt that conflict between role players remains predominant in the institution and is linked to the entrenchment of ineffective processes and systems. One of the directors had the following to say about the institution's SCM systems and processes:

'We have to adopt systems and processes of a better design. Automated programming is required to improve the speed of our processes. We are too slow and bureaucratic.' (P6, male, 46 years)

An executive added that a technological and innovative drive was needed in the institution to drive SCM processes. This is indicated in the excerpt below:

'We need innovation and technology to change our lives. I think it is vital that we look at the electronic means of supplying documents to smoothen the process. We also need to look at augmenting our current Enterprise Resource Planning [ERP] system for improved controls and reducing the risks within the SCM processes.' (P11, female, 51 years)

The consensus from the participants was that the institution could increase the use of innovation and technology to enhance the implementation of SCM. The feedback from participants also shows that the institution's processes are mostly manual and that there is a lack of a centralised supplier database at the institution. This translates to inconsistent business processes characterised by prolonged lead times in evaluating, adjudication, awarding and processing of SCM-related transactions. Furthermore, the lack of a centralised supplier database impedes the prospect of fairness and transparency in SCM and leads to a proliferation of numerous suppliers, some who are unworthy to be considered as partners by the organisation, in this case, the university (Burt Petcavage \& Pinkerton 2011). The study also showed that there had been inconsistent reporting of SCM-related information, which leads to the amplified risk 
of fraud, corruption and losses. All these irregularities tend to weaken the internal control system because of inconsistent processes and procedures and will ultimately hamper the measurement of SCM improvements.

\section{Theme 4: Procurement policy and practices}

The fourth theme that emerged in the study is procurement policy and practices. The views of participants suggest that the institution is lacking an appropriate policy that supports the implementation of SCM. The following quote from an executive manager at the institution reflects the inadequacy of the institution's current policy:

'For the implementation of the SCM policy, we require a policy guide and complementary procedures, and without an updated policy, it is going to be difficult for the institution to excel in this area.' (P13, female, 55 years)

Another senior lecturer at the institution also bemoaned the institution's current policy by stating:

'I think we need to revise the procurement policy and we need to get a comprehensive step-by-step procedure manual that is an implementation guide.' (P17, male, 48 years)

Another executive manager at the institution alluded to the need for a continued review of the institution's SCM policies as the institution evolves to guarantee that they remain relevant to the operations and objectives of the institution. This view is captured in the excerpt below from one of the middle-level managers:

'Our SCM policies must not be cast on stone. Instead, as the environment changes these policies and practices should also change. I, therefore, feel that as an institution we must revise our policies.' (P2, female, 40 years)

Most of the participants were in agreement about the ineptness of the institution's current policy and practices. The lack of a relevant policy guide translates to the institution's failure to improve its SCM practices as reflected by the audit findings of both the institution's internal and external audit reports. Furthermore, the lack of appropriate policy and procedures leads to uncertainty about which standards are to be followed and clouds the necessary transparency in the SCM processes. Also, as stated in a report by the National Treasury (2015), the ineffectiveness of the available policy, its inability to blend with the existing legal framework and its non-alignment to best practice equate to zero governance. This often results in fraudulent activities such as nepotism, cover-quoting, collusion, forgery and conflict of interest.

\section{Theme 5: Supply chain management implementation}

Implementation of SCM emerged as the fifth theme of the study. Most participants were of the view that there is no diligent effort by institutional management to implement SCM. Some of the participants cited the inability of management to embrace a progressive culture that realises the strategic nature of SCM. Other participants could not identify any area where the institution had excelled in implementing SCM. These views are supported by the following excerpt from an executive director:
'Institutional management has not fully embraced SCM. As such, there has been no concerted effort to implement the current policy, even though the policy has its own shortcomings.' (P15, male, 57 years)

Some participants were of the view that the institution has not transitioned from procurement into SCM, as stipulated by the South African public sector procurement reform drive. One of the directors had the following to say in support of this view:

'I think the biggest challenge is moving from the procurement into SCM.' (P12, male, 36 years)

It is commonly acknowledged that the development of suitable policies neither leads to their implementation nor facilitates the further development of relevant strategies within institutions. It is implementation that gives life to policy and embeds it into the institutional practices and processes (Rolfstam 2013). As the practice of SCM accounts for a big chunk of expenditure for a higher education institution's annual spend, a well-performing SCM division is critical to attaining the strategic objectives and goals of the institution (Lember, Kattel \& Kalvet 2014). The South African National Treasury allocates the responsibility of developing and executing appropriate SCM to senior officials, but the strategy cascades to all levels of the organisation (National Treasury 2010). This depicts that while SCM strategy is developed at strategic, executive and management level, it is to be applied and practised at all organisational levels if positive results are to be realised. The lack of a resolute SCM implementation drive at the institution points to poor alignment between institutional strategies, demand management and SCM planning, such that the institution does not get value for its money from most of its SCM activities.

\section{Theme 6: Stakeholder change management}

The sixth theme arising in the study is stakeholder change management. The participants further noted that management community did not have a pro-active approach towards change as they were in the habit of reacting to developments, instead of having some strategies in place beforehand. An executive director had the following to say:

'I feel that change management should be brought into a place where people are taken through every element of SCM, and that will assist the institution to embrace the concept.' (P8, male, 54 years)

Further, regarding the issue of changing the institution's way of operating, participants suggested that the importance of training and development should be realised. The following excerpt from another director support this view:

'I think in my view there is a need to ensure that people are taken through workshops to understand the SCM policy and procedures, as well as the implications of the adherence and non-adherence to them.' (P7, female, 44 years)

A senior lecturer further pointed to the need for the stimulation of change, through the use of education and training: 
'I think a lot of education and training has to be done where we unpack the SCM policy to the stakeholders. In this way, changes will be embraced as managers and staff adopt new attitudes.' (P17, male, 48 years)

Participants indicated that the limited understanding of SCM within the institution was attributed to ineffective communication, training and education of stakeholders. They further linked the lack of stakeholder buy-in to the limited stakeholder engagement and communication by those who are tasked with the implementation of SCM. The lack of cooperation between the institution's managers and stakeholders has eroded the integrity of and the trust in the institution's SCM processes. Integrity violations such as abuse and manipulation of procedures as well as the waste and abuse of institutional resources expose the institution to the risk that funds, resources and assets are not utilised for their intended purposes and the greater good of the institution.

\section{Theme 7: Human resource management}

Human resources management-related issues emerged as the seventh theme in this study. The participants expressed discontentment regarding the skills level of the incumbents in the institution's procurement division. The following sentiment from another director presents this view:

'I think what needs to be done is to get people with the requisite knowledge and skills. I don't know if we have staff who have these technical skills internally in the SCM division.' (P3, female, 50 years)

Other participants were of the view that human resource challenges such as capacity, unsuitable qualifications and skills shortages were prevalent in the institution. One of the executives had the following to say about this:

'We need to strengthen the capability of the SCM division through the development of technical skills. We need to get people with the right technical skills who are competent and have the right experience. We have to address the capability in terms of human capital in the supply chain division.' (P10, male, 47 years)

Participants further suggested that there is a need to develop an appropriate organisational structure and to design a skills dictionary for the various positions on the structure to integrate the different stages of the supply chain. Participants felt that such an action would ensure the correct placement of employees within the SCM division. From the feelings expressed by the participants, it appears that the institution faces organisational capacity challenges that include organisational design and development, leadership challenges, resource limitations, lack of delegation frameworks and limited management systems. These entrenched human resource limitations reflect the problems faced by the institution when attempting to execute key SCM activities effectively. This is because overall institutional performance is based on the combined performances of the available human resources, who participate in both operational and strategic activities (Gómez-Cedeño et al. 2015). Without an adequately skilled workforce which is prepared to assume the roles of SCM professionals, problems within this area are likely to persist leading to the underperformance of both the available personnel and the entire institution.

\section{Theme 8: Organisational culture}

Organisational culture emerged as the eighth theme of the study. The majority of the participants were of the opinion that the institution's organisational culture was a barrier to the successful implementation of SCM. Below is an excerpt from a manager who echoed this sentiment:

'I think culture can eat strategy for breakfast in that if you don't have the right culture you are not going to succeed. So, the culture in this institution is to operate like a family business. We have been with each other for a long while, and there is just a culture of no consequence.' ( $\mathrm{P} 1$, female, 39 years)

The excerpt below from one of the senior managers further places spotlight on this matter:

'You also get the age-old thing at the institution of staff who have been doing things in a particular way, and it`s just that natural resistance to breaking away from it.' (P16, male, 54 years)

Another manager lamented the culture of non-compliance in the institution, as indicated in the following quote:

'There is the organisational attitude of non-compliance. That is arguably the most significant challenge that this institution faces in the execution of SCM practices.' (P5, female, 34 years)

The employees and their morals, values and norms create an organisational culture which is a product of external adaptation and internal incorporation (Cao et al. 2015). Some scholars see culture as relatively stable and resistant to change, which makes it very difficult to alter the status quo (Chandler, Heidrich \& Kasa 2013). It is not always that resistance to change is explicit; it is often indirect and, in most organisations, is eliminated by attitudes of the leadership (Prado, Kalid \& Archibald 2017). As shown through the views of participants, the institution might be in need of a cultural overhaul if SCM is to be successfully executed. Implementation of SCM is an act of cultural renaissance in managerial practices as they have to transition the institution from the current state where there is a devotion to outdated business models which may no longer be relevant in today's higher educational environment (Cao et al. 2015). A culture of consequence management has to be stimulated to address any institutional malpractices currently rooted in the SCM system. Of particular concern is the culture of non-compliance with SCM regulations, which is one of the factors actuating the poor performance of SCM. Attitudinal changes are therefore needed to ensure that role players execute their SCM-related duties prudently.

\section{Conclusion}

This study aimed to explore the internal barriers to the implementation of SCM at a South African traditional university. Eight themes were highlighted through the analysis of the qualitative data collected from various role players at the institution. The study revealed that implementation of 
SCM is unlikely to be successful if the support of stakeholders is not obtained before its application. As long as these stakeholders have not embraced the concept, they will be unable to support its implementation holistically within the institution. Because of the existing lack of transparency, these key stakeholder groups will perceive that the process is questionable and may either exclude themselves and disregard the outcomes of SCM transactions or campaign both formally and informally for the disruption of essential activities at the institution. Since SCM is a dynamic concept that has evolved over the years, many stakeholders in the institution are yet to understand it fully. As a result of this lack of knowledge of SCM, the primary focus is now being directed to procurement, which is marginal when compared to the strategic implications associated with SCM. The study further revealed that current policies are outdated such that they no longer address the current needs of the institution. Change management emerged as another theme, as there is an established tendency of depending on past practices (reinventing the wheel) without attempting to innovate in the area of SCM. It also emerged that there is a shortage of manpower that is adequately skilled in SCM, which has triggered much of the current underperformance. Still, an organisational culture characterised by resistance to change and non-compliance to laid down guidelines and procedures remains ingrained in the institution. The study, therefore, concludes that SCM in the institution is hampered by various internal barriers, each which is unique and requires specific managerial attention to address it.

\section{Managerial implications}

Various solutions can be assumed in dealing with the eight internal barriers realised in this study. Stakeholder relationship management initiatives should be put in place within the institution. Some of these initiatives include supplier development, meetings and workshops for buyer-supplier interactions and improved reporting mechanisms for various stakeholders on issues related to SCM. To streamline SCM implementation, the institution should favour the use of automated or online SCM systems which have proven to be useful in the gaining of competitive advantages and restructuring organisational processes (Mahdillou \& Akbary 2014). Furthermore, a centralised supplier database should be developed and updated regularly to enable data mining for trends analysis, accurate costings and improved planning. It is further essential to integrate all SCM systems with other institutional systems to ensure that there is systemic interaction in operations, planning and accurate reporting. Policy-related irregularities may be addressed by amending the institution's SCM policy and procedures, and this should be supported by robust compliance monitoring and consequence management. It is further crucial that competent and knowledgeable supply chain professionals be recruited and remunerated sufficiently to retain them. However, given the shortage of experienced supply chain professionals in South Africa, it may be necessary to initiate graduate development programmes where suitable graduates from universities are recruited and developed to take over key supply chain-related positions upon completion of these programmes. Also, the change management models such as Kotter's Eight-Step Change Management Process, the Deming Cycle of Plan-Do-Check-Act and the Change Management Foundation (Anderson 2013) could be espoused to develop a more enabling organisational culture.

\section{Limitations and suggestions for future research}

The study is limited in that it is a case study that is based on a single higher education institution, which is located in one South African province. As a result, caution should be exercised in generalising the findings of the study to other higher education institutions and environments. As mentioned by Simon and Goes (2013), although case studies may be indicative of what happens in other organisations, additional research may be required to prove these suggestions in different contexts. Another limitation of the study relates to its dependence on the qualitative research approach, which produces subjective findings because of researcher bias and its heavy reliance on the skills and experience of the researcher (Griffin 2014). In this case, application of the same study to a larger number of public higher education institutions may yield different or richer data for analysis (Wallance \& Sheldon 2015). Also, given that this study focused on the internal barriers to the implementation of SCM practices, future studies could focus on external barriers to obtain a balanced view of the barriers to SCM in the institution.

\section{Acknowledgements Competing interests}

The authors declare that they have no financial or personal relationships that may have inappropriately influenced them in writing this article.

\section{Authors' contributions}

M.Z.M. did the literature review and collected the data. C.M. performed the data analysis and compiled the sections of the article.

\section{References}

Akyel, N., Polat, K. \& Arslankaya, S., 2012, 'Strategic planning in institutions of higher education: A case study of Sakarya University', Procedia - Social and Behavioral Sciences 58, 66-72. https://doi.org/10.1016/j.sbspro.2012.09.979

Al-Turki, U.M., Duffuaa, S., Ayar, T. \& Demirel, O., 2008, 'Stakeholders integration in higher education: Supply chain approach', European Journal of Engineering Education 33(2), 211-219. https://doi.org/10.1080/03043790801980136

Ambe, I.M. \& Badenhorst-Weiss, J.A., 2011, Managing and controlling public sector supply chains, Supply Chain Management, P. Li (ed.), Supply Chain Management, pp. 72-93, InTech Europe, Slavka Krautzeka.

Ambe, I.M. \& Badenhorst-Weiss, J.A., 2012, 'Supply chain management challenges in South African public sector', African Journal of Business Management 6(44), 11003-11014. https://doi.org/10.5897/AJBM12.360

Anderson, J., 2013, The lean change method: Managing agile organizational transformation using Kanban, and lean startup thinking, viewed 11 March 2018, from https://leanpub.com/leanchangemethod.

Anney, V.N., 2015, 'Ensuring the quality of the findings of qualitative research: Looking at trustworthiness criteria', Journal of Emerging Trends in Educational Research and Policy Studies 5(2), 272-281. 
Auditor General South Africa (AGSA), 2011, A keen focus on supply chain management by government will help to build confidence in our democracy, viewed 10 June 2017, from http://www.agsa.co.za/portals/0/AG/A_keen_focus_on_supply chain_management_by_government_will_help_to_build_confidence_in_our democracy.pdf

Bhattacherjee, A., 2012, Social science research: Principles, methods and practices, Creative Common Attribution edn., University of South FloridaTampa, FL.

Bhorat, H., Cassim, A. \& Tseng, D., 2016, 'Higher education, employment and economic growth: Exploring the interactions', Development Southern Africa 33(3), 312-327. https://doi.org/10.1080/0376835X.2016.1161501

Blumberg, B.F., Cooper, D.R. \& Schindler, P.S., 2014, Business research methods, 4th edn., McGraw-Hill Education, Maidenhead.

Boulton, G. \& Lucas, C., 2011, 'What are universities for'? Chinese Science Bulletin 56(23), 2506-2517. https://doi.org/10.1007/s11434-011-4608-7

Bryman, A., 2015, Social research methods, 5th edn., University Press, London.

Bunting, I. \& Cloete, N., 2010, 'Institutional types in higher education in South Africa', in PowerPoint Presentation for the Council for Higher Education Session,
February 2010, viewed 30 April 2018, from file:///C:/Users/20090419/ February 2010, viewed 30 April 2018, from file:///C:/Users/20090419/
Downloads/Session $\% 202 \mathrm{a} \% 20$ Institutional\%20Types $\% 20 \mathrm{in} \% 20 \mathrm{SA} \% 20 \mathrm{HE} \% 20$ - $\%$ 20lan \%20Bunting.pdf

Burger, P., 2016. Between the devil and deep blue sea? The financing of higher education view 28 May 2017, from http///www. education, viewed 28 May 2017, from http://www.econ3x3.org/sites/default/ files/articles/Burger $\% 20 \mathrm{P} \% 202016 \% 20 \mathrm{C}$
higher\%20education $\% 20-\% 20$ INAL2.pdf

Burt, D., Petcavage, S. \& Pinkerton, R., 2010, Supply management, McGraw-Hill, New York.

Business Tech, 2015, How South Africa's universities spend their money, 07 November viewed 30 April 2018, from https://businesstech.co.za/news/government/103073/ how-south-africas-universities-spend-their-money/

Cao, Z., Huo, B., Li, Y. \& Zhao, X., 2015, 'The impact of organizational culture on supply chain integration: A contingency and configuration approach', Supply Chain Management: An International Journal 20(1), 24-41.

Chandler, N., Heidrich, B. \& Kasa, R., 2013, 'Everything changes? A repeated crosssectional study of organisational culture in the public sector', Evidence-based HRM: A Global Forum for Empirical Scholarship 5(3), 283-296. https://doi.org/10.1108/ EBHRM-03-2017-0018

Cohen, L., Manion, L. \& Morrison, K., 2011, Research methods in education, 7th edn. Routledge, Abingdon.

Creswell, J.W., 2013, Qualitative inquiry and research design: Choosing among five approaches, Sage, Los Angeles, CA.

De la Rey, C., 2015, Governance and management in higher education: 2nd national higher education summit, University of South Africa, Pretoria.

Department of Higher Education and Training, 2014, Regulations for reporting by public higher education institutions, DHET, Pretoria.

Dlamini, W., 2016, 'Determining Procurement best practices in South African comprehensive universities', Masters dissertation, University of South Africa, Pretoria.

Dlamini, W. \& Ambe, I., 2012, The influence of public procurement policies on the implementation of procurement best practices in South African universities, UNISA Pretoria.

Dlamini, W. \& Ambe, I.M., 2013, 'An analysis of procurement best practices in the University of South Africa', Journal of Contemporary Management 10, 100-116.

Doody, O. \& Noonan, M., 2013, 'Preparing and conducting interviews to collect data', Nursing Researcher 20(5), 28-32. https://doi.org/10.7748/nr2013.05.20.5.28.e327

Flick, U., 2014, The SAGE handbook of qualitative data analysis, viewed 15 May 2017, from http://www.sagepub.com/upm-data/588969_Flick_TheSAGE_HB_of_ Qualitative_Data_Analysis.pdf

Fooladvand, M., Yarmohammadian, M.H. \& Shahtalebi, S., 2015, 'The application strategic planning and balance scorecard modelling in enhance of higher strategic planning and balance scorecard modelling in enhance of higher education', Procedia-Social and Beh
org/10.1016/j.sbspro.2015.04.115

Fourie, D., 2015, 'Procurement in the South African public service: A reflection of the ethical and legislative framework', Public and Municipal Finance 4(2), 38-45.

Gill, P., Stewart, K., Treasure, E. \& Chadwick, B., 2008, 'Methods of data collection in qualitative research: Interviews and focus groups', British Dental Journal 204(6), 291-295. https://doi.org/10.1038/bdj.2008.192

Gómez-Cedeño, M., Castán-Farrero, J.S., Guitart-Tarrés, L. \& Matute-Vallejo, J., 2015 'Impact of human resources on supply chain management and performance', Industrial Management \& Data Systems 115(1), 129-157. https://doi.org/10.1108/ IMDS-09-2014-0246

Gopalakrishnan, G., 2015, 'How to apply academic supply chain management: The case of an international university', Management 20(1), 207-221.

Griffin, C., 2014, The advantages and limitations of qualitative research psychology and education, viewed 30 June 2017, from http://www.pseve.org/Annals_el/ UPLOAD/griffin2.pdf

Hassan, S., Ramli, S.H., Roslan, R. \& Jaafar, J., 2015, 'Supplier performance management at higher education institutes', Procedia Economics and Finance 31, 671-676. https://doi.org/10.1016/S2212-5671(15)01155-7

Jennex, M.E. \& Durcikova, A., 2013, 'Assessing knowledge loss risk', in 2013 46th Hawail International Conference on System Sciences, Hawaii, January 7-10, viewed 11 March 2013 from, https://www.computer.org/csdl/proceedings/hicss/2013/ 4892/00/4892d478.pdf
Jonker, J. \& Penning, B., 2010, The essence of research methodology: A concise guide for Master and PhD students in management science, Springer, Berlin and Heidelberg.

Kimenyi, M.S., 2011, 'Contribution of higher education to economic development: A survey of international evidence', Journal of African Economies 20(3), 314-349. https://doi.org/10.1093/jae/ejr018

Kotecha, P., Wilson-Strydom, M. \& Fongwa, S.M. (eds.), 2012, Chapter 12: South Africa. In: Higher education data: A profile of higher education in Southern Africa, SARUA, Johannesburg, pp. 75-85.

KPMG South Africa, 2016a, The economics of \#FeesMustFall: Economic challenges to accessing tertiary education and providing tuition-free universities in South Africa, viewed 11 May 2017, from www.sabloq.kpmg.co.za

KPMG South Africa, 2016b, Making higher education procurement work, viewed 30 April 2018, from https://assets.kpmg.com/content/dam/kpmg/za/pdf/2016/11/ Making-Higher-Education-Procurement-Work.pdf

Lau, A.K., 2007, 'Educational supply chain management: A case study', On the Horizon 15(1), 15-27. https://doi.org/10.1108/10748120710735239

Leedy, P.D. \& Ormrod, J.E., 2015, Practical research planning and design, 11th edn., Pearson, Harlow.

Lember, V., Kattel, R. \& Kalvet, T., 2014, Public procurement, innovation and policy: International perspectives, Springer, Heidelberg, Germany.

Mahdillou, H. \& Akbary, J., 2014, 'E-procurement adoption, its benefits and costs', Bachelor's thesis, School of Engineering, University of Boras, viewed 11 March 2018, from http://bada.hb.se/bitstream/2320/14364/1/Mahdillou\%20 Akbary.pdf

Mason, M., 2010, 'Sample size and saturation in PhD studies using qualitative interviews', Forum Qualitative Sozialforschung/Forum: Qualitative Social Research 11(3), viewed 11 March 2018, from http://www.qualitative-research.net/index $\mathrm{php/fqs/article/view/1428/3027}$

Matolong, M.J., 2015, Guidelines for establishing an effective supply chain management framework for local municipalities, North-West University, Potchefstroom.

Mayer, I., 2015, 'Qualitative research with a focus on qualitative data analysis', International Journal of Sales, Retailing and Marketing 4(9), 53-67.

Mkhize, Z., 2004, Supply chain management conference: Transforming government procurement system, 22-23 November, National Treasury, Republic of South Africa, Durban.

Moon, K., Brewer, T.D., Januchowski-Hartley, S.R., Adams, V.M. \& Blackman, D.A., 2016, 'A guideline to improve qualitative social science publishing in ecology and conversation', Journals Ecology and Society 21(3), 1167-1177.

Moretti, F., Van Vliet, L., Bensing, J., Deledda, G., Mazzi, M., Rimondini, M. et al., 2011 'A standardized approach to qualitative content analysis of focus group discussions from different countries', Patient Education and Counselling 82, 420-428. https:// doi.org/10.1016/j.pec.2011.01.005

National Planning Commission, 2012, National development plan 2030 - Executive summary, viewed 30 April 2018, from file:///C:/Users/20090419/Downloads/ NPC\%20National\%20Development \%20Plan\%20Vision\%202030\%20-lo-res.pdf

National Treasury, 2010, Contracts management framework, Department of National Treasury, Pretoria.

National Treasury, 2015, Public sector supply chain management review, Department of National Treasury, Pretoria.

$\mathrm{Nel}$, J., 2010, Developing a conceptual framework to analyse supply chain design practices, PhD Thesis, University of South Africa, Pretoria.

Nicolaides, A., 2014, 'Research and innovation - The drivers of economic development', African Journal of Hospitality, Tourism and Leisure 3(2), 1-16.

Owusu-Bio, M.K., Manso, J.F. \& Adiwokor, E., 2015, 'Mapping the internal supply chain for educational institutions. A case study of Kwame Nkrumah University of Science and Technology', European Journal of Business and Management 7(23), 32-42.

Padget, D., 2012, Qualitative methods in social work research, 3rd edn., Sage Publications, Los Angeles, CA.

Parliamentary Monitoring Group., 2013, Universities under administration: Update by Department of Higher Education and Training: Africa Institute of South Africa Act Repeal bill (B6B-2013): Adoption, NCOP Education and Recreation, Cape Town.

Patton, M.Q., 2015, Qualitative research and evaluation methods, 3rd edn., Sage, Thousand Oaks, CA.

Petty, N.J., Thompson, O.P. \& Stew, G., 2012, 'Ready for a paradigm shift? Part 1: Introducing the philosophy of qualitative research', Manual Therapy 17, 267-274. https://doi.org/10.1016/j.math.2012.03.006

Poluha, R.G., 2016, The quintessence of supply chain management: What you really need to know to manage your processes in procurement, manufacturing, warehousing and logistics (Quintessence Series), 1st edn., Springer Heidelberg, New York, Dordrecht, London.

Pouris, A. \& Inglesi-Lotz, R., 2014, 'The contribution of higher education institutions to the South African economy', South African Journal of Science 110(3), 1-5. https:// doi.org/10.1590/sajs.2014/a0059

Prado, D., Kalid, R. \& Archibald, R., 2017, 'Culture eats strategy: Impact on disruptive change programs', PM World Journal 6(9), 1-18.

PricewaterhouseCoopers, 2015, Higher Education pitfalls in procurement, Higher Education Seminar, August 2015, viewed 30 April 2018, from https://www.pwc. co.za/en/assets/pdf/he-conference_pitfalls-in-procurement.pdf 
PricewaterhouseCoopers, 2016, Supply chain management in the higher education sector, PWC, Cape Town, pp. 1-3.

Rolfstam, M., 2013, Public procurement and innovation: The role of institutions, Edward Elgar Publishing, Cheltenham.

Ruzic-Dimitrijevic, L., 2014, 'Risk assessment of knowledge management system' Journal of Applied Knowledge Management 3(2), 114-126.

Sallaudin, H., Siti, H.R., Rahmat, R. \& Jimisiah, J., 2015, 'Supplier performance management at higher education institution', Procedia Economics and Finance 31 671-676. https://doi.org/10.1016/S2212-5671(15)01155-7

Saunders, M., Lewis, P. \& Thornhill, A., 2015, Research methods for business students, 7th edn, Pearson Education, Harlow.

Simon, M.K. \& Goes, J., 2013, Scope limitation and delimitations, viewed 20 July 2017 from http://dissertationrecipes.com/wp-content/uploads/2011/04/limitation scopedelimitation1.pdf

South Africa Education, 2018, South African Higher Education Institutions, viewed 08 March 2018, from http://www.southafricaeducation.info/Higher-Education/ List-of-Higher-Education-Institutions-in-South-Africa.htm
Turley, L. \& Perera, O., 2014, Implementing sustainable public procurement in South Africa: Where to start, International Institute for Sustainable Development Report May 2014, viewed 09 February 2018, from http://www.iisd.org/sites/default/files/ publications/implementing_spp_south_africa.pdf

Universities South Africa, 2015, 2nd national higher education summit: Annexure 5 reflections on higher education transformation, Universities South Africa, Pretoria.

Uyarra, E., 2010, 'Conceptualizing the regional roles of universities, implications and contradictions', European Planning Studies 18(8), 1227-1246. https://doi.org/ $10.1080 / 09654311003791275$

Yates, J. \& Leggett, T., 2016, 'Qualitative research: Introduction', Radiologic Technology $88(2), 225-231$.

Wallance, M. \& Sheldon, N., 2015, 'Business research ethics: Participant observer perspectives', Journal of Business Ethics 128(2), 267-277. https://doi.org/10.1007/ s10551-014-2102-2

Watermeyer, R.B., 2011, Regulating public procurement in Southern Africa through international and national standards, viewed 09 March 2018, from http://www. ssinc.co.za/Files/Doc/RBWPapers/T3-18.pdf 